\title{
Scientific note:Varroa jacobsoni and $V$. destructor on hill and plains strains of Apis cerana in southern India
}

\author{
Chet Prasad BhatTA ${ }^{1,2}$, M. S. ReddY ${ }^{3}$, Deborah Roan SMItH $^{1}$ \\ ${ }^{1}$ Department of Ecology and Evolutionary Biology, University of Kansas, Haworth Hall, 1200 Sunnyside Avenue, Lawrence, KS \\ 66045, USA \\ ${ }^{2}$ Department of Biology, Radford University Carilion, Roanoke, VA 24013, USA \\ ${ }^{3}$ Department of Zoology, Center for Apiculture Studies, Jnana Bharathi, Bengaluru 560 056, India
}

Received 8 July 2019 - Revised 11 October 2019 - Accepted 10 November 2019

\begin{abstract}
Two types of Apis cerana are known from India: black or hill bees and yellow or plains bees, which differ in mitochondrial haplotype. We investigated whether black and yellow A. cerana host different species or strains of Varroa. Apis. cerana and any associated Varroa mites were collected from 21 colonies (5 with Varroa), in Bengaluru, India, and surrounding areas. Bees were scored for color and mitochondrial haplotype using sequences of the cytochrome oxidase I and II genes and the intervening leucine tRNA gene and non-coding region. Mites were scored for species and strain using partial sequence of cytochrome oxidase I. We found both $V$. destructor with a haplotype similar to the previously reported Sri Lankal and a novel haplotype of V. jacobsoni. Contrary to our expectations, we found no association of mite species and bee mitochondrial haplotype.
\end{abstract}

\section{mitochondrial DNA / host-parasite coevolution / Apis cerana / Varroa / India / Varroa jacobsoni / Varroa destructor}

Anderson and Trueman (2000) recognized Varroa destructor Anderson and Trueman 2000 and V. jacobsoni Oudemans, 1904 as separate, cryptic species with broadly allopatric geographic and host ranges. Two genetic strains of $V$. destructor from northeast Asia, the Japan and the Korea strains, have successfully made the transition from the original host, Apis cerana Fabricius, 1793 to the novel host Apis mellifera Linnaeus, 1758 and become one of the most serious threats to A. mellifera beekeeping. V. destructor's impact on A. mellifera has led to extensive study of geographically structured genetic variation in both $V$. destructor and V. jacobsoni .

Geographic structuring of mtDNA variation in $V$. destructor and $V$. jacobsoni populations is broadly congruent with the geographic structuring of mtDNA variation in A. cerana (Anderson and Trueman 2000; Navajas et al. 2010; Smith and Hagen 1996; Smith 2011;

Corresponding author: D. Smith, debsmith@ku.eduR. Smith, debsmith@ku.edu

Handling Editor: Peter Rosenkranz
Warrit et al. 2006; Zhou et al. 2004). V. jacobsoni parasitizes southern lineages of $A$. cerana, primarily those occupying lands on the Sunda shelf, which were intermittently united to the mainland during Pleistocene glacial periods. This includes Indonesia, peninsular and Bornean Malaysia, peninsular Thailand south of $\sim 11^{\circ}$ $\mathrm{N}$, and probably adjacent areas (Smith and Hagen 1996; Smith 2011). Varroa destructor is found on lineages of A. cerana across most of mainland Asia, including Korea, Japan, China, and Thailand north of $\sim 11^{\circ} \mathrm{N}$ (Navajas et al. 2010).

India is home to two varieties of A. cerana-the yellow or plains bee and the black or hill bee (see, for example, Kapil 1956). These are characterized by differences in coloration, mating flight time (Oldroyd et al. 2006), and mtDNA haplotype (Smith and Hagen 1996). We had an opportunity to investigate A. cerana and Varroa from Bengaluru (Bangalore), India and surrounding areas March 3-5, 2014, with the goal of determining whether one or both mite species were present, the mites' mitochondrial haplotypes, and whether the hill and plain bees were host to different mites. Both the bee and the mite samples were preserved in $90 \%$ ethanol; mites were stored together in 
one vial with A. cerana workers from their host nests. These specimens were loaned to the University of Kansas Snow Entomological Collection by author MSR for purposes of identification.
We sampled 21 colonies of A. cerana, 5 of which contained mites. We classed bees as black, yellow, or brown (darker yellow) (1) by scoring the amount and distribution of yellow coloration on the first three

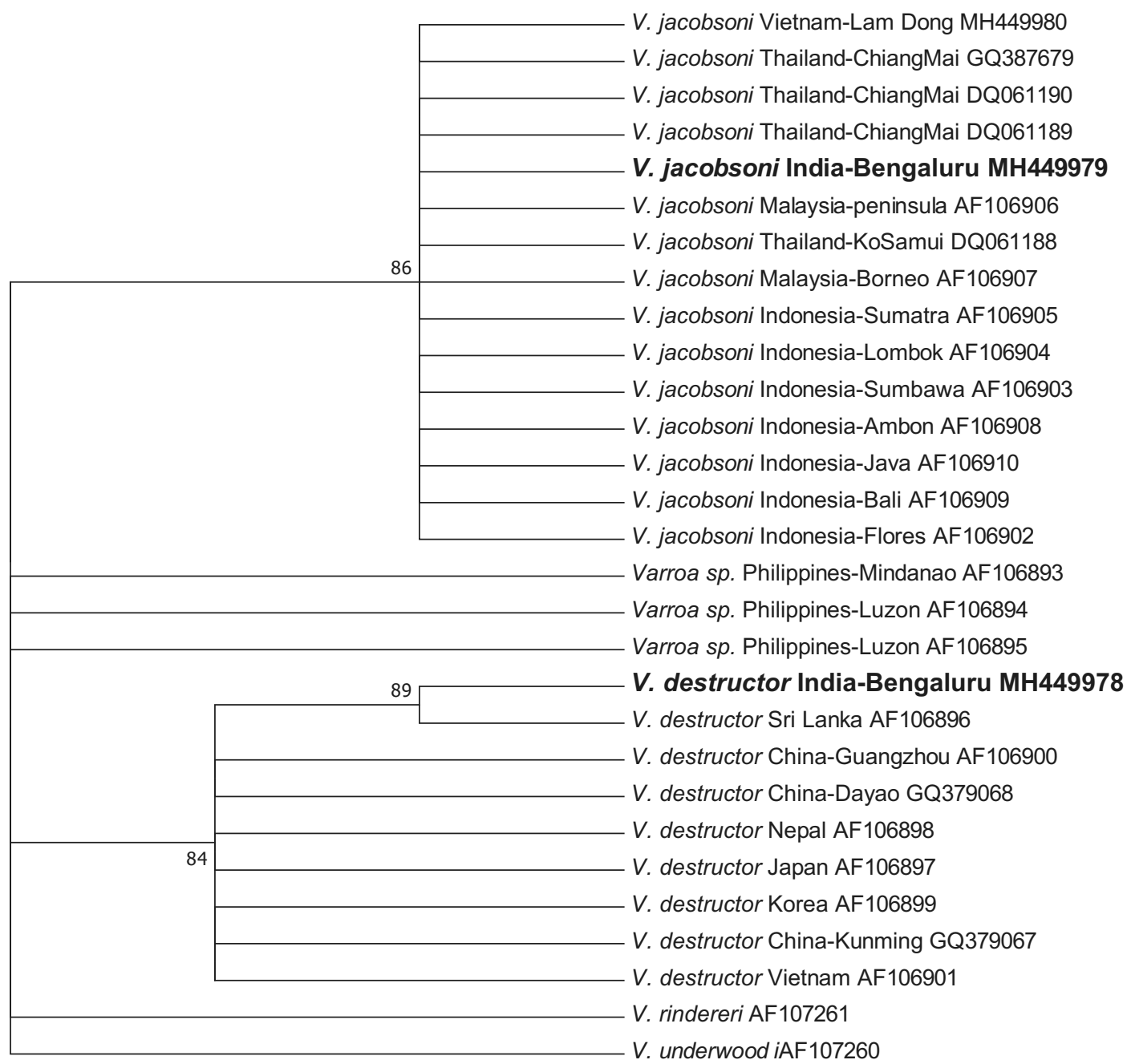

Fig. 1 Phylogenetic tree showing that indigenous Indian Varroa include both $V$. destructor and $V$. jacobsoni. $V$. destructor and V. jacobsoni samples each form well-supported, monophyletic groups. Haplotype SouthIndia1, (V. destructor India-Bengaluru MH449978) groups with V. destructor, haplotype Bengaluru1 (V. jacobsoni IndiaBengaluru MH449979) groups with $V$. jacobsoni. Bootstrap consensus tree showing relationships among $V$. destructor and $V$. jacobsoni cytochrome oxidase I partial sequences was constructed using maximum likelihood and the HKY+G model of sequence evolution (Hasegawa et al. 1985) with 500 bootstrap replications, implemented in MEGA7 (Kumar et al. 2016). Branches with less than $80 \%$ bootstrap support were collapsed; bootstrap supports of $80 \%$ or greater shown above branches. Varroa rindereri and V. underwoodi were used to root the tree. Each sequence shown is unique and, except for V. rindereri and $V$. underwoodi, from Varroa collected from A. cerana. Duplicate sequences and $V$. destructor collected from A. mellifera were not used in tree-building. Sequences are named by species + place of collection + GenBank accession number. The two haplotypes found in this study are shown in larger boldface type. 
metasomal tergites of five worker bees per nest (Ruttner 1988; Oldroyd et al. 2006), and (2) sequencing a mitochondrial fragment (comprising a portion of the COI gene, non-coding region, leucine tRNA, and a portion of the COII gene) from one or two workers from nests without or with Varroa, respectively (primers as in Hall and Smith 1991; PCR protocol as in Smith and Hagen 1996, Warrit et al. 2006). PCR products were prepared for sequencing using ExoSAP-IT PCR Product Cleanup Reagent as described by the manufacturer (Thermo Fisher Scientific, Waltham, MA, USA). Sequences were compared with gene sequences from known black and yellow Indian bees collected in Bengaluru in August, 1991 (Smith and Hagen 1996).

We found that most of the A. cerana colonies carried mtDNA haplotypes characteristic of the black or hill variety: 14 black, 6 yellow, and one abandoned nest with no bees, only free-running mites present. Workers from all 14 nests carrying black or hill variety mtDNA were also visually scored as black; those from the 6 nests carrying yellow or plains mtDNA were scored as yellow or brown.

We used primers V-51F (5'-GTAATTTGTATACA AAGAGGG-3') and V-1400R (5'-CAAT ATCAATAGAAGAATTAGC-3') to amplify a 328-bp fragment of the mitochondrial COI gene of 5-6 Varroa from each of the five nests with mites (see Warrit et al. 2006 for PCR conditions). This fragment is located at positions 1888 to 2215 on the complete mitochondrial genome of V. destructor (GenBank AJ493124.2; Evans and Lopez 2002). Sequencing and trimming yielded $280 \mathrm{bp}$ of sequence corresponding to the sequences presented by Anderson and Trueman (2000).

To determine if our Varroa sequences were novel or had been reported previously, we compared them with $V$. destructor collected from A. cerana (AF106896,
AF106900, GQ379068, AF106898, AF106897, AF106901, GQ379067, AF106899), V. jacobsoni (GQ387679, DQ061190, DQ061188, AF106906, AF106907, AF106910, AF106910, AF106909, AF106908, AF106905, AF106902, AF106904, AF106903), and Philippine Varroa (AF106893, AF106894, AF106895). To assign our Varroa sequences to $V$. destructor or $V$. jacobsoni, we constructed a phylogenetic tree using the maximum likelihood method in Mega 7.0 (Kumar et al. 2016) and the best model of substitutions obtained for our data. We used one exemplar of each of the two distinct haplotypes obtained from our Indian mites, representative sequences of $V$. destructor and $V$. jacobsoni, and V. rindereri de Guzman and DelfinadoBaker, 1996 (AF107261) and V. underwoodi DelfinadoBaker and Aggarwal, 1987 (AF107260) as outgroups to root the tree (Anderson and Trueman 2000; Navajas et al. 2010, Warrit et al. 2006, Zhou et al. 2004). Results are shown in Fig. 1.

Both $V$. jacobsoni and $V$. destructor were present in the A. cerana hives we examined. The Indian $V$. destructor haplotype found here (GenBank accession \# MH449978) differs by just two bases from the haplotype reported from Sri Lanka (Sri Lanka1; Anderson and Trueman 2000; GenBank Accession AF106896); we call it $V$. destructor haplotype South India1. Our $V$. jacobsoni haplotype (GenBank accession \# MH449979) did not match any previously reported haplotypes in Genbank or in the literature; we call it $V$. jacobsoni haplotype Bengaluru1. Table I shows the mtDNA haplotypes of the mites in the five $A$. cerana hives with mites (one lacking bees). There appeared to be no correlation of mite species and bee strain; however, our sample of nests carrying mites was very small, and we could not always observe whether the mites

Table I. Varroa species present in colonies of Apis cerana in southern India. Apis cerana type (black or yellow) and Varroa species identifications based on mitochondrial cytochrome oxidase I sequence data. Five or six mites sampled per nest. Sites 1 and 2 were small apiaries in Bengaluru on the Bangalore-Mysore road; site 3 was a roof-top home apiary, Kamakshipalya neighborhood, Bengaluru.

\begin{tabular}{|c|c|c|c|c|c|}
\hline Nest & Collection site & Nest condition & A. cerana haplotype & Varroa destructor & Varroa jacobsoni \\
\hline 2014-11 & Site 1 & $\begin{array}{l}\text { Adult workers and } \\
\text { drone brood present }\end{array}$ & Black & 0 & 5 \\
\hline 2014-12 & Site 2 & $\begin{array}{l}\text { Adult workers and } \\
\text { drone brood present }\end{array}$ & Yellow & 1 & 4 \\
\hline 2014-19 & Site 3 & $\begin{array}{l}\text { No workers; } \\
\text { drone brood present }\end{array}$ & Yellow & 4 & 1 \\
\hline 2014-20 & Site 3 & $\begin{array}{l}\text { Adult workers and } \\
\text { drone brood present }\end{array}$ & Yellow & 5 & 1 \\
\hline 2014-21 & Site 3 & $\begin{array}{l}\text { No bees present; } \\
\text { mites on comb }\end{array}$ & No bees & 5 & 0 \\
\hline
\end{tabular}


were successfully reproducing in the nests from which they were collected. Thus, though we can say that both $V$. destructor and $V$. jacobsoni with a novel COI sequence are present on A. cerana in India, we cannot yet determine if the two Varroa species are selective regarding which type of A. cerana they reproduce on.

\section{ACKNOWLEDGEMENTS}

This work was supported in part by USDA grant 2010-65104-20533 to Olav Rueppell and DRS. DNA sequencing was carried out at the Idaho State University Molecular Research Core Facility, Idaho State University, Pocatello, ID, USA. We thank Dr. Annupamaa for her invaluable help in making collections.

\section{AUTHORS' CONTRIBUTIONS}

DRS conceived this research and carried out collections; CPB and DRS carried out laboratory analyses of the bee and mite specimens; MSR coordinated travel and collecting in and around Bengaluru; DRS and CPB wrote the paper and participated in the revisions of it. All authors read and approved the final manuscript.

\section{COM P L I A N C E W I T H E T H ICAL STANDARDS}

Conflict of interest The authors declare that they have no conflict of interest.

\section{REFERENCES}

Anderson, D.L., Trueman, J.W.H. (2000) Varroa jacobsoni (Acari : Varroidae) is more than one species. Exp. Appl. Acarol. 24:165-189.

Evans, J.D., Lopez, D.L. (2002) Complete mitochondrial DNA sequence of the important honey bee pest, Varroa destructor
(Acari: Varroidae). Exp. Appl. Acarol. 27: 69-78. https://doi. org/10.1023/A:1021574306010

Hall, H.G., Smith, D.R. (1991) Distinguishing African and European honeybee matrilines using amplified mitochondrial DNA. PNAS USA 88:4548-4552.

Hasegawa, M., Kishino, H., Yano. T. (1985) Dating the human-ape split by a molecular clock of mitochondrial DNA. J. of Mol. Evol. 22:160-174.

Kapil, R.P. (1956) Variation in biometrical characters of the Indian honey-bee (Apis indica F.), Indian J. Entomol. 18:440-457.

Kumar, S., Stecher, G., Tamura, K. (2016) MEGA7: molecular evolutionary genetics analysis version 7.0 for bigger datasets. Mol. Biol. Evol. 33:1870-1874. doi:https://doi.org/10.1093 /molbev/msw054

Navajas, M., Anderson, D.L., de Guzman, L.I, Huang, Z.Y., Clement, J., Zhou, T., Le Conte, Y. (2010) New Asian types of Varroa destructor: a potential new threat for world apiculture. Apidologie 41:181-193. doi:https://doi.org/10.1051 /apido/2009068

Oldroyd, B.P., Reddy, M.S., Chapman, N.C., Thompson, G.J., Beekman, M. (2006) Evidence for reproductive isolation between two colour morphs of cavity nesting honey bees (Apis) in south India. Insectes Sociaux 53:428-434. doi:https://doi. org/10.1007/s00040-005-0889-2

Ruttner, F. (1988) Biogeography and taxonomy of honeybees. Springer-Verlag, Berlin.

Smith, D.R. (2011) Asian honey bees and mitochondrial DNA. In: Hepburn HR, Radloff SE (eds) Honeybees of Asia. Springer Verlag, Berlin, pp 69-93.

Smith, D.R., Hagen, R.H. (1996) The biogeography of Apis cerana as revealed by mitochondrial DNA sequence data. J. Kans. Entomol. Soc. 69:294-310.

Warrit, N., Smith, D.R., Lekprayoon, C. (2006) Genetic subpopulations of Varroa mites and their Apis cerana hosts in Thailand. Apidologie 37:19-30. doi:https://doi.org/10.1051 /apido:2005051

Zhou, T., Anderson, D.L., Huang, Z.Y., Huang, S.X., Yao, J., Ken, T., Zhang, Q.W. (2004) Identification of Varroa mites (Acari : Varroidae) infesting Apis cerana and Apis mellifera in China. Apidologie 35:645-654. doi:https://doi.org/10.1051 /apido:2004059

Publisher's note Springer Nature remains neutral with regard to jurisdictional claims in published maps and institutional affiliations. 